\title{
Ecotones as indicators: boundary properties in wetland-woodland transition zones
}

\author{
G. Brownstein ${ }^{1,2,4}$ C. Johns ${ }^{2}$, A. Fletcher ${ }^{2}$, D. Pritchard ${ }^{3}$ and P. D. Erskine ${ }^{2}$ \\ ${ }^{1}$ Landcare Research, 764 Cumberland St, Dunedin 9016, New Zealand \\ ${ }^{2}$ Centre for Mined Land Rehabilitation, Sustainable Minerals Institute, The University of Queensland, Brisbane, \\ QLD 4072, Australia \\ ${ }^{3}$ Department of Marine Science, University of Otago, Dunedin 9054, New Zealand \\ ${ }_{4}$ Corresponding author. E-mail: brownsteing@landcareresearch.co.nz
}

Keywords: Anthropogenic impact, Beta diversity, Functional groups, Vegetation monitoring.

\begin{abstract}
Ecotones, representing the transition zones between species or communities, have been suggested as focal points for detecting early shifts in vegetation composition due to anthropogenic impact. Here we examined if changes in ecotone location or properties can be used as reliable indicators of hydrological change in temperate wetland communities. We examined 38 woodland-wetland-woodland transitions, distributed across four sites with different anthropogenic disturbance histories and hydrological traits. We tested whether: 1) the ecotones are associated with environmental gradients, and 2) the location or properties of these ecotones change with disturbance history. Well-defined ecotones were associated with steep gradients in soil depth and soil moisture. Most ecotones showed a change in vegetation from hydrophytic to dryland species. There was also some evidence that in highly disturbed sites the link between ecotones and environmental gradients was less apparent. By sampling across boundaries we can better understand the factors controlling the distribution of species. This allows us to make better predictions about the impacts of anthropogenic change in wetland communities. By investigating the transitions between different vegetation communities we were able to highlight key indicators that could be used to monitor these ecologically sensitive and diverse wetland communities.
\end{abstract}

Abbreviations: Ate - Amphibious, fluctuation-tolerating, emergent, ATw - Amphibious, fluctuation-tolerating, woody, Tda Terrestrial damp, Tdr - Terrestrial dry, VWC - Volumetric Water Content, WPFG - Water Plant Functional Groups.

\section{Introduction}

Ecotones, transition zones occurring where the environmental limits of species and communities overlap, have frequently been suggested as focal points for detecting early shifts in community composition due to disturbance (Allen and Breshears 1998, Stohlgren et al. 2000, Batllori et al. 2010, Aune et al. 2011, Mathisen et al. 2014). Ecotone shifts are frequently considered at large scales (e.g., mountain ranges or continental level), often in the context of climate change (e.g., Aune et al. 2011, Mathisen et al. 2014), but such shifts can also occur at more localised scales (e.g., forest or wetland edges) and be driven by a range of other factors (Cornet et al. 1992). Monitoring data on changes in ecotone location or properties may be used to inform conservation and management decisions, but before reliable predictions about the effects of disturbance on ecotones can be made, a better understanding of landscape processes occurring at community boundaries is required (Cadenasso et al. 2003, Ries et al. 2004, Hofgaard et al. 2012). Here we set out to determine the likely effects of anthropogenic disturbance to hydrology on wetland-woodland vegetation ecotones by characterising the links between site traits (e.g., hydrology and disturbance history) and ecotone location and properties.
Ecotones can be either gradients or discontinuities (i.e., gradual or sharp) controlled by environmental conditions, habitat availability, disturbance or biotic interactions. The identity of ecotones (i.e., the type and extent of community composition shifts) can vary spatially and temporally (Danz et al. 2013). Ecotones and their properties have been described in a wide range of systems; along gradients of bird distributions (Williams et al. 1999), at grassland-forest edges (Danz et al. 2013, Erdős et al. 2013) and at wetlandforest boundaries (Carter et al. 1994, Kirkman et al. 1998, Brownstein et al. 2013); in both natural and modified habitats (Lloyd et al. 2000, Walker et al. 2003). However, studies of vegetation dynamics in ecotones often report findings that are contradictory or inconsistent with each other and there is little agreement about how ecotones function. For example, some authors predict that increased environmental variability and a greater range of environmental niches might drive higher species richness within the ecotones than in adjoining communities, while others predict that species richness will be lower in ecotones due to stress from environmental fluctuation (van der Maarel 1976, Lek-Ang et al. 2007, Liu and Cui 2009) or that relative species richness is unpredictable, driven by stochastic distribution of resources (Ries et al. 2004). Some of this inconsistency could be attributable to differences in the spatial and temporal resolutions under study (Danz et al. 
2013) or the lack of sufficient information from which to derive commonalities. It is clear that a better understanding of ecotones and the factors that create and maintain them could increase our ability to predict shifts in ecotone properties (Stohlgren et al. 2000).

In this study, we examine patterns of species richness, beta diversity, and functional group presence across woodland-wetland-woodland vegetation sequences from four sites, to determine how they relate to gradients in soil moisture and soil depth and differences in water regime and disturbance history between sites. We test the hypothesis that a greater range of environmental niches in the ecotone would result in higher species richness, beta diversity and a greater number of functional groups within ecotones, compared to adjacent vegetation communities. Based on our findings, we discuss ecotone traits that could provide sensitive indicators of hydrological change for wetland monitoring.

\section{Methods}

This study was conducted on the Newnes Plateau situated approximately $20 \mathrm{~km}$ northeast of Lithgow in the Blue Mountains, Australia $\left(33^{\circ} 23 \mathrm{~S}, 150^{\circ} 12 \mathrm{E}\right)$. The Newnes Plateau covers more than $400 \mathrm{~km}^{2}$, with elevations ranging between $950 \mathrm{~m}$ and $1300 \mathrm{~m}$ above mean sea level. The area experiences a climate with mean monthly temperature ranging between $9^{\circ} \mathrm{C}$ and $24^{\circ} \mathrm{C}$, and a mean annual temperature of $17^{\circ} \mathrm{C}$ (since 1991 at Mount Boyce $35 \mathrm{~km}$ to the South; bom. gov.au last visited on 23, October 2012). Mean monthly precipitation ranges between $44 \mathrm{~mm}$ and $129 \mathrm{~mm}$, with a mean annual rainfall of $953 \mathrm{~mm}$ (since 1994).

The Newnes Plateau is floristically diverse with approximately 590 native plant species (Royal Botanical Gardens and Domain Trust, http://www.rbgsyd.nsw.gov.au, accessed 14, March 2013) in a mosaic of forest, woodland, heath and shrub swamps over Triassic sandstone. The Newnes Plateau is a floristically important area because it contains several endangered plant species and communities, including the Newnes Plateau Shrub Swamps which are protected as Endangered Ecological Communities under New South Wales legislation (DEC 2006). Newnes Plateau Shrub Swamps are located on periodically to permanently waterlogged alluvial soils along open drainage lines; and are characterized by a dense to sparse shrub canopy and sedge understory with occasional emergent eucalypt trees (Benson and Baird 2012). The surrounding vegetation is characterised by tall eucalypt forests and woodlands with a diverse moderately dense shrub and herb layer (DEC 2006) and boundaries between communities evident as a sharp ( $2 \mathrm{~m}$ to $3 \mathrm{~m}$ wide) vegetation transition seemingly related to moisture availability (Benson and Baird 2012). The potential anthropogenic impacts on the hydrology of these communities include lowering of water tables (related to underground mining) or increased volume of intermittent surface flows of water pumped from underground mines. If the properties of the woodland/wetland ecotones are closely related to the hydrological regime, then changes in hydrology should alter the location and properties of the ecotones, providing an indicator of impact.
The data presented here were collected from four Newnes Plateau shrub swamps (sites) with varying hydrology: West Wolgan, Bungleboori North, Sunnyside East and Narrow Swamp. West Wolgan ('damp' hydrology, i.e., intermittentlysaturated peat-swamps that have water tables that fluctuate extensively based on availability of surface runoff from recent rainfall) is $220 \mathrm{~m}$ long and $30 \mathrm{~m}$ wide, it sits in a small, bowl-like depression in the landscape with no surface water. Bungleboori North ('wet' hydrology, i.e., permanently-saturated peat-swamps that are maintained in a constantly wet state by groundwater and surface flows) is $180 \mathrm{~m}$ long and $60 \mathrm{~m}$ wide, it too sits in a small depression in the landscape but much of the wetland has standing water with a flowing stream through the centre. Sunnyside East ('mixed' hydrology, i.e., contains areas of peat-swamp similar to both 'wet' and 'damp' types) is $1000 \mathrm{~m}$ long and on average $40 \mathrm{~m}$ wide; this wetland slopes northeast along a steep-sided valley floor spanning a hydrological gradient from dry/damp with a fluctuating water table at the top end to wet with a stable water table and stream at the low end. Narrow Swamp ('impacted' hydrology, this site had artificially high volumes of surface flow in previous years due to mine waste-water discharge and when this ceased, there was a marked decrease in flow and substantial drop in water table) is $900 \mathrm{~m}$ long and on average $30 \mathrm{~m}$ wide; this wetland runs northeast along the bottom of a steep-sided valley. All four sites are surrounded by open eucalypt woodland.

\section{Sampling methods}

Depending on the size of the wetland, between 3 and 14 transects were placed to span the width the wetland plus $10 \mathrm{~m}$ either side and spaced between $50 \mathrm{~m}$ to $175 \mathrm{~m}$ apart (Table 1). Before going in the field, the start locations of each transect were located on along the edge of the mapped wetland boundary (using the vegetation maps produced by OEH, 2012) using randomly selected points generated in ArcGIS10.1 (ESRI, CA, USA). Each transect was laid out perpendicular to the mapped wetland boundary and extended $10 \mathrm{~m}$ inside the eucalypt woodland from the mapped woodland/wetland boundary. In the field, the location of each random transect was located using a GPS (with an accuracy of $\sim 5 \mathrm{~m}$ ). Transect length ranged between $40 \mathrm{~m}$ to $96 \mathrm{~m}$ depending on width of the wetland.

\section{Species data}

Starting from $0 \mathrm{~m}$ on the transect, sets of four $1 \mathrm{~m}^{2}$ contiguous quadrats were placed every $8 \mathrm{~m}$ along each transect (i.e., a $4 \mathrm{~m}$ gap between every set of four $1 \mathrm{~m}^{2}$ quadrats, Figure 1). Prior experience in sampling these swamps suggested that a narrow ecotone of $2 \mathrm{~m}$ to $3 \mathrm{~m}$ wide could be expected. We set the start of the sampling so that at least one set of contiguous quadrats overlapped the woodland/wetland edge, at least one set of $4 \mathrm{~m} \times 1 \mathrm{~m}$ contiguous quadrats was located completely inside the woodland, and at least one set was positioned inside the wetland. In each quadrat, the percentage cover of each species (shoot presence) was visually estimated. Plants 
Table 1. Details of number of transects and ecotones surveyed at each site. Transects spanned the width of the wetland, however regular placement of quadrats meant that that sometimes both boundary areas (ecotones) were not sampled.

\begin{tabular}{lccc}
\hline \multicolumn{1}{c}{ Site } & Hydrology & $\begin{array}{c}\text { Number of } \\
\text { transects }\end{array}$ & Ecotones \\
\hline West Wolgan & Damp & 3 & 4 \\
Bungleboori North & Wet & 4 & 5 \\
Sunnyside East & Mixed & 14 & 16 \\
Narrow Swamp & Impacted & 7 & 13 \\
\hline
\end{tabular}

were classified into water plant functional groups (WPFG) based on relative inundation tolerance, how they respond to fluctuations in water depth, and life form (sensu Casanova 2011, Table 2); the number of functional groups per quadrat was then calculated. Beta diversity $\left(\beta_{c}\right)$, a measure of continuity, or the average change in species composition between quadrats (Koleff et al. 2003) was calculated using the 'betadiver' function in the 'vegan' package in R (Oksanen et al. 2011).

\section{Environmental variables}

Starting from $0 \mathrm{~m}$ on each transect, we measured soil moisture (\% VWC) and depth $(\mathrm{cm})$ every $2 \mathrm{~m}$ along the full transect length (two readings, $\sim 0.5 \mathrm{~m}$ apart, were averaged for each point). Soil moisture was measured using a HydroSense II CD658 (Campbell Scientific, Australia) soil moisture probe. Soil depth recorded to the nearest $5 \mathrm{~cm}$ and was measured by pushing a $2 \mathrm{~m}$ long, $1 \mathrm{~cm}$ diameter steel rod marked at $10 \mathrm{~cm}$ intervals into the ground.

\section{Data analysis}

All data analyses were performed using R (R Development Core Team 2011). For soil characters, the rate of change (the first derivative) was calculated along each transect using moving window analysis (with a window five data points wide). We chose to examine rate of change (the absolute value of the slope of the line) as we were interested in how fast the environmental variables were changing rather than the actual values (e.g., we were not interested in if the wetland had higher soil moisture than woodland).

Quadrats were classified into one of three location categories: 'ecotone' (quadrats within the boundary between vegetation types), 'wetland' (quadrats dominated by wetland vegetation i.e., species belonging to 'amphibious' or 'aquatic' water plant functional groups) and 'woodland' (dominated by woodland vegetation, i.e., species belonging to 'terrestrial' plant functional groups). To examine if ecotones quadrats differ from woodland and wetland quadrats in species richness, beta diversity, the number functional groups, absolute and relative change soil moisture, and absolute and relative change in soil depth, ANOVAs were performed at the wetland level for each factor using the Anova function in the 'car' package (Fox and Weisberg 2010). Post-hoc pairwise comparison of locations was conducted, using t-tests with pooled standard deviation (with a Bonferroni adjustment), when the 'location' and/or 'location by transect' term was significant in the ANOVA.

\section{Results}

Species

Plots of species presence and abundance along each transect showed clear patterns of species association/community change along environmental gradients. Most ecotone areas were made up of a mixture of species from both wood-

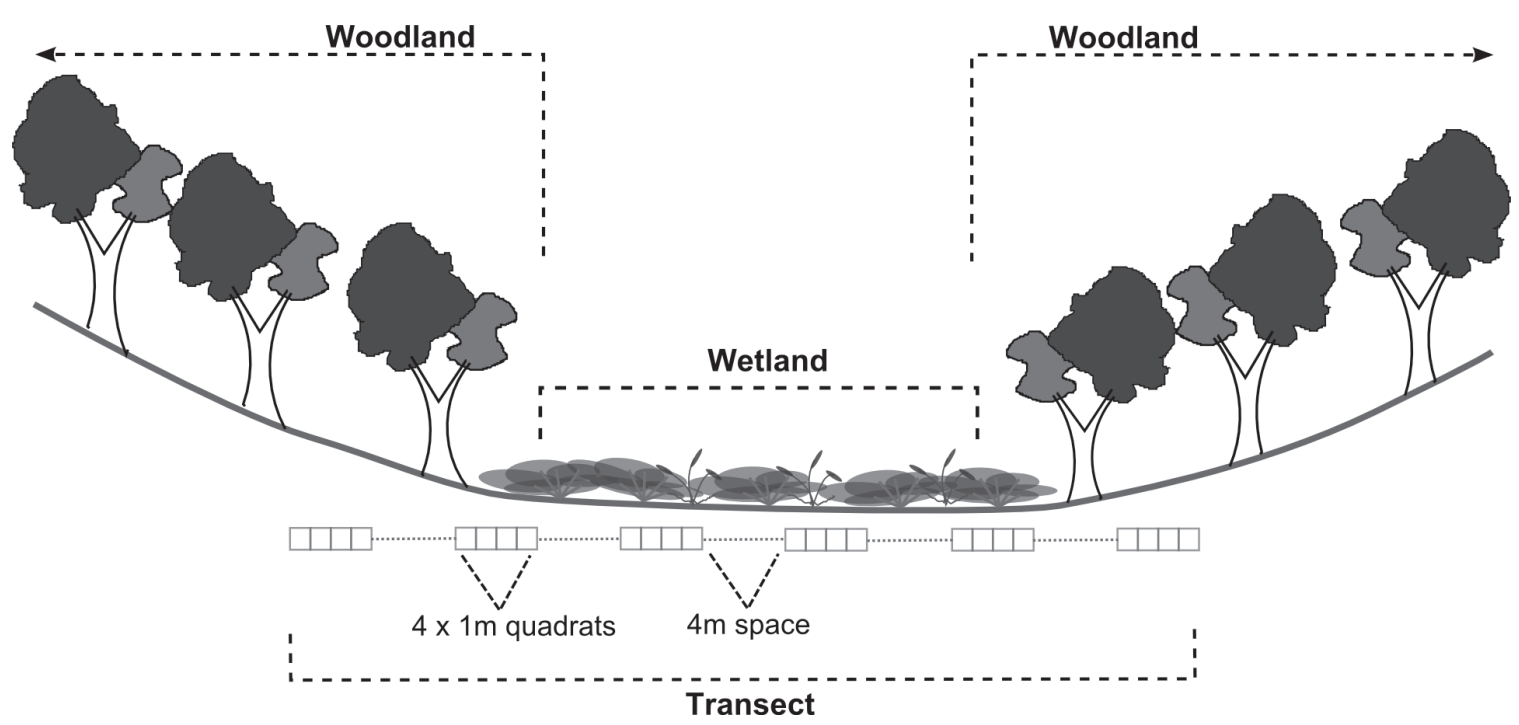

Figure 1. Conceptual diagram of sampling layout across the woodland-wetland-woodland transitions. The transects extend from $10 \mathrm{~m}$ inside the eucalypt woodland edge across the wetland to $10 \mathrm{~m}$ inside the eucalypt woodland on the far side. Transects were placed to ensure at least 1 ecotone / boundary region was sampled (see the methods section for further details). 
Table 2. Wetland Plant Functional Groups (WPFG) used here and definitions from Casanova (2011).

\begin{tabular}{ll}
\hline \multicolumn{1}{c}{ WPFG } & Definition \\
\hline Terrestrial (T) & Species that lack adaptations for survival during prolonged inundation. \\
Tdr & Terrestrial dry habitat spp. \\
Tda & Terrestrial damp habitat spp. i.e., typically found in moist habitats. \\
\hline Amphibious (A) & Species that tolerate fluctuations in water level (i.e., flooding and drying) \\
ATe & Amphibious fluctuation-tolerators, emergent growth form. \\
ATl & Amphibious fluctuation-tolerators, low-growing. \\
ATw & Amphibious fluctuation-tolerators, woody growth form. \\
ARp & $\begin{array}{l}\text { Amphibious fluctuation-responders, plastic (i.e., display morphological plasticity according to water } \\
\text { presence/absence). }\end{array}$ \\
\hline
\end{tabular}

land and wetland communities (Table A.1 species list for each swamp). Six species were found solely in the ecotones, although each species had a cover of $6 \%$ or less and were only recorded in one site (Table A.1).

The number of species in each quadrat (local species richness) in ecotones tended to be mid-way between that of the woodland and wetland quadrats (Figure 2a). In wet and mixed hydrology sites, local species richness in the wetland quadrats was significantly lower than ecotone and woodland quadrats, while in the damp site the local species richness was significantly lower in the woodland quadrats compared to wetland and ecotone quadrats, and in the impacted site there was no difference between the three locations (Figure 2a, Table 3).

Beta diversity $\left(\beta_{c}\right)$ in the ecotone quadrats, was mid-way between $\beta_{\mathrm{c}}$ in the woodland and wetland quadrats in three sites, though only significantly different from both woodland and wetland in the mixed hydrology site (Figure 2b). In the impacted site $\beta_{c}$ was higher (though not significantly so) in the ecotone quadrats than either woodland or wetland quadrats (Figure $2 b$ ). Impacted, mixed and wet sites had significantly lower $\beta_{\mathrm{c}}$ in the wetland quadrats than the woodland quadrats.

\section{Functional groups}

Seven plant functional groups were detected across the four sites (Table A1). In both the impacted and damp sites the number of groups per quadrat was significantly lower in the woodland quadrats compared to the ecotone and wetland quadrats; while in the wet site the wetland quadrats had significantly lower number of groups compared with the ecotone and woodland quadrats (Figure 2c, Table 4).

The most abundant amphibious groups were amphibious, fluctuation-tolerating, emergent (ATe) and amphibious, fluctuation-tolerating, woody (ATw) species (Figure 3). The ATe group accounting for between $35 \%$ and $70 \%$ and ATw group accounting for 12 to $40 \%$ of the proportional cover in the wetland quadrats, across all sites. In wet, mixed and damp sites there were significant differences in the proportion of
ATe cover between ecotone, woodland and wetland quadrats, with ecotone quadrats mid-way between woodland and wetland quadrats; while for the impacted site there was no significant difference between the ecotone and wetland quadrats (Figure 3a, Table 4). The proportional cover of ATw group was highest in the wetland quadrats and significantly different from the woodland quadrats for all four sites (Figure 3b).

The proportion of total cover represented by the terrestrial damp (Tda) habitat species group ranged between less than $1 \%$ (wet site wetland quadrats) and 17\% (damp site wetland quadrats, Figure 3c, Table 4). The proportion Tda cover in the woodland quadrats was significantly higher than in wetland quadrats in the mixed site; and mid-way between the ecotone and wetland quadrats in wet, damp and impacted sites.

The proportion of terrestrial dry (Tdr) habitat species group cover in the ecotone quadrats was mid-way between woodland and wetland quadrats, with all locations significantly different at the site level (Figure $3 \mathrm{~d}$, Table 4). The proportion of Tdr cover ranged between $10 \%$ (wet site wetland quadrats) and $75 \%$ (damp site woodland quadrats).

\section{Abiotic factors}

Soil moisture changed more sharply in the ecotone quadrats than the wetland and woodland quadrats in the wet, mixed and damp sites (though change was significantly faster in the damp hydrology site only). At the impacted hydrology site, soil moisture changed more quickly (though not significantly so) in both ecotone and wetland quadrats than woodland quadrats (Figure 4a, Table 5). Change in soil depth tended to be sharper in the ecotone quadrats for the mixed and impacted sites (though not significantly so, Fig. 4b).

\section{Discussion}

We sampled across 38 ecotones in the four wetland/ woodland sites. Although some ecotones provided evidence to support our a priori hypothesis (i.e., they were associated with steeper gradients in soil moisture or soil depth), most did not. Further, although there was turnover in species com- 
Table 3. ANOVA tables for the analysis of variance on linear models for species richness and beta $\mathrm{c}$ at each site. Significant terms (p $<0.05)$ are in bold.

\begin{tabular}{llrrrrr}
\hline \multirow{2}{*}{ Site } & & \multicolumn{2}{c}{ Species Richness } & \multicolumn{2}{c}{$\beta_{\mathrm{c}}$} \\
\cline { 3 - 7 } & & df & \multicolumn{1}{c}{ SS } & F & SS & F \\
\hline \multirow{2}{*}{ West Wolgan } & Location & 2 & 266.23 & $\mathbf{1 9 . 7 8}$ & 6.28 & 1.45 \\
& Location:Transect & 3 & 59.67 & $\mathbf{2 . 9 5}$ & 9.76 & 1.5 \\
\hline \multirow{2}{*}{ Bungleboori } & Location & 2 & 315.91 & $\mathbf{1 3 . 8}$ & 110.08 & $\mathbf{1 3 . 3 4}$ \\
& Lorth & 9 & 154.49 & 1.5 & 46.9 & 1.26 \\
\hline \multirow{2}{*}{ Sunnyside } & Location:Transect & 2 & 298.03 & $\mathbf{3 4 . 7 1}$ & 112.93 & $\mathbf{3 8 . 6 1}$ \\
East & Location:Transect & 33 & 560.42 & $\mathbf{3 . 6 5}$ & 175.63 & $\mathbf{3 . 6 3}$ \\
\hline \multirow{2}{*}{ Narrow } & Location & 2 & 14.19 & 0.657 & 24.91 & $\mathbf{3 . 2 7}$ \\
Swamp & Location:Transect & 17 & 567.61 & $\mathbf{3 . 0 9}$ & 78.42 & 1.28 \\
\hline
\end{tabular}
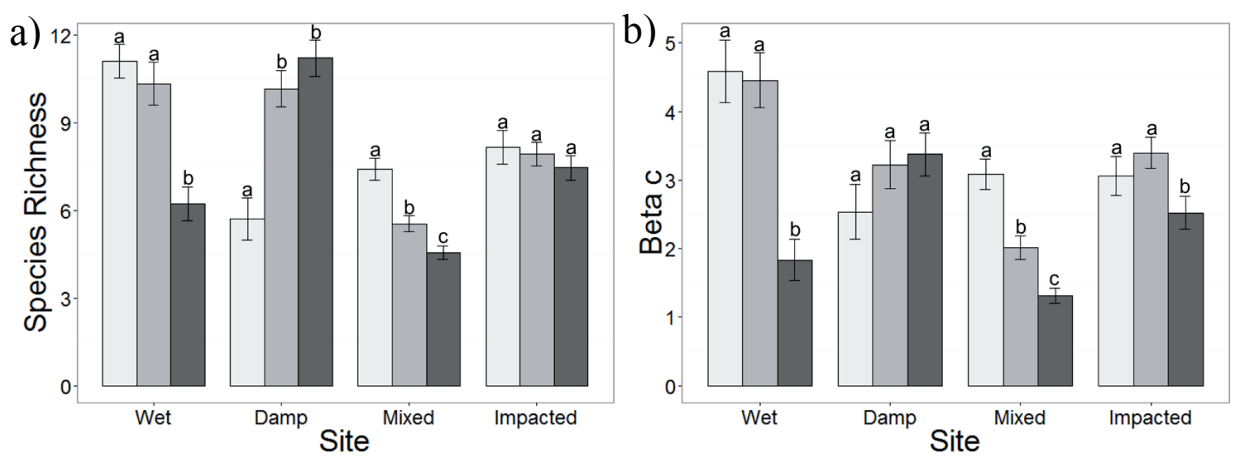

c)

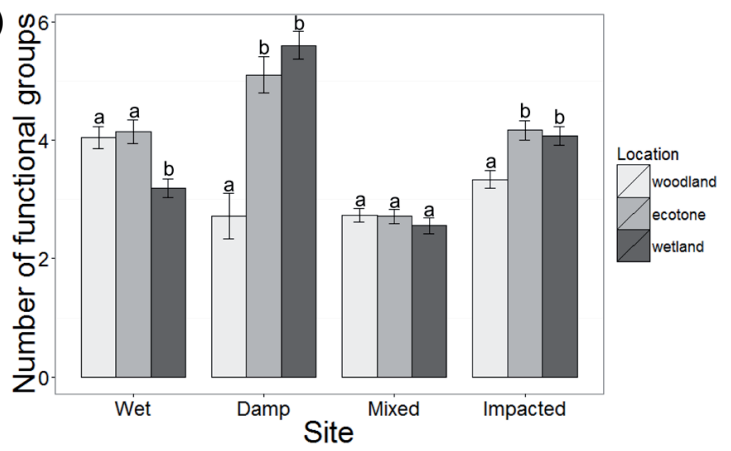

Figure 2. Comparison of a) local species richness (number of species per quadrat, b) Beta $\mathrm{C}$ (Beta diversity) and c) number of functional groups found in woodland, ecotone and wetland quadrats for each of the sites; within each site letters indicate significant differences between locations.

position across the ecotone only one ecological property, functional group distribution, showed consistent patterns of change across all ecotones; thus providing weak support for our a priori hypothesis. By investigating the transitions between vegetation communities we were able to highlight key functional groups that could be used to monitor these ecologically sensitive and diverse wetland communities. Below we discuss our findings further, in relation to current theory surrounding ecotones.

Conflicting theories and evidence for ecotones predict that parameters are higher, lower or intermediate compared to the values found in the neighbouring areas (Lloyd et al. 2000, Ries et al. 2004, McIntire and Fortin 2006, Brownstein et al. 2013). Some predict species richness should be higher within the ecotone than in adjoining communities due to a greater number of potential niches, while others predict species richness to be lower due to stress from environmental fluctuation (van der Maarel 1976, Lek-Ang et al. 2007, Liu and Cui 2009). Here the ecotone values were intermediate between the woodland and wetland areas for most measures in most wetlands (although most were not statistically different). The intermediate values in species richness and functional group 
Table 4. ANOVA tables for the analysis of variance on linear models for functional groups at each site. Significant $(p<0.05)$ terms are in bold.

\begin{tabular}{|c|c|c|c|c|c|c|c|c|c|c|c|c|}
\hline \multirow[b]{2}{*}{ Site } & & \multirow[b]{2}{*}{ df } & \multicolumn{2}{|c|}{ Number of groups } & \multicolumn{2}{|c|}{ Proportion Ate } & \multicolumn{2}{|c|}{ Proportion Atw } & \multicolumn{2}{|c|}{ Proportion Tda } & \multicolumn{2}{|c|}{ Proportion Tdr } \\
\hline & & & SS & $\mathrm{F}$ & SS & $\mathrm{F}$ & SS & $\mathrm{F}$ & SS & $\mathrm{F}$ & SS & $\mathrm{F}$ \\
\hline \multirow{2}{*}{ West Wolgan } & Location & 2 & 74.54 & 28.7 & 1.11 & 15.24 & 0.19 & 3.93 & 0.22 & 7.11 & 3.13 & 21.46 \\
\hline & Location:Transect & 3 & 21.12 & 5.42 & 0.51 & 4.69 & 0.06 & 0.85 & 0.01 & 0.21 & 0.36 & 1.68 \\
\hline \multirow{2}{*}{$\begin{array}{l}\text { Bungleboori } \\
\text { North }\end{array}$} & Location & 2 & 13.68 & 7.02 & 2.36 & 29.2 & 1.24 & 23.78 & 0.039 & 5.55 & 3.69 & 32.45 \\
\hline & Location:Transect & 9 & 7.22 & 0.82 & 0.3 & 0.83 & 1.26 & 5.39 & 0.057 & 1.8 & 0.41 & 0.81 \\
\hline \multirow{2}{*}{ Sunnyside East } & Location & 2 & 1.43 & 0.77 & 10.19 & 83.05 & 0.57 & 16.7 & 0.0062 & 5.16 & 11.17 & 94.84 \\
\hline & Location:Transect & 33 & 77.66 & 2.53 & 6.19 & 3.05 & 3.24 & 5.71 & 0.005 & 2.54 & 4.98 & 2.56 \\
\hline \multirow{2}{*}{$\begin{array}{l}\text { Narrow } \\
\text { Swamp }\end{array}$} & Location & 2 & 23.14 & 8.87 & 1.19 & 10.34 & 1.25 & 13.62 & 0.33 & 11.39 & 9.08 & 72.44 \\
\hline & Location:Transect & 17 & 76.59 & 3.45 & 4.4 & 4.47 & 3.72 & 4.75 & 0.96 & 3.82 & 1.65 & 1.55 \\
\hline
\end{tabular}

a)

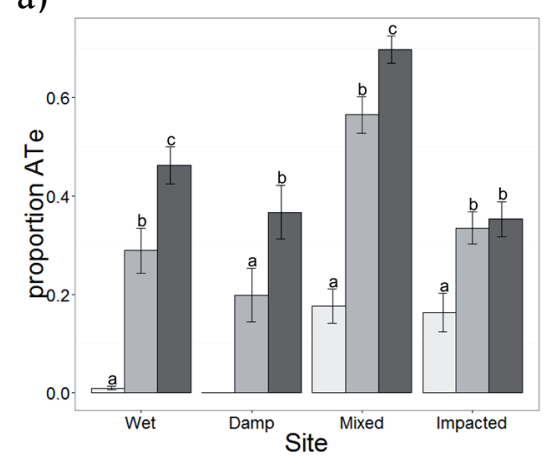

c)

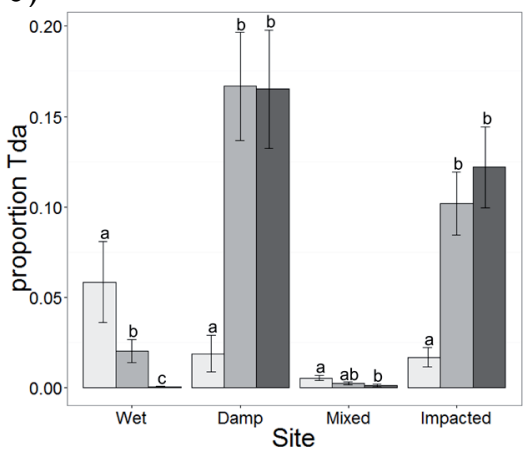

b)

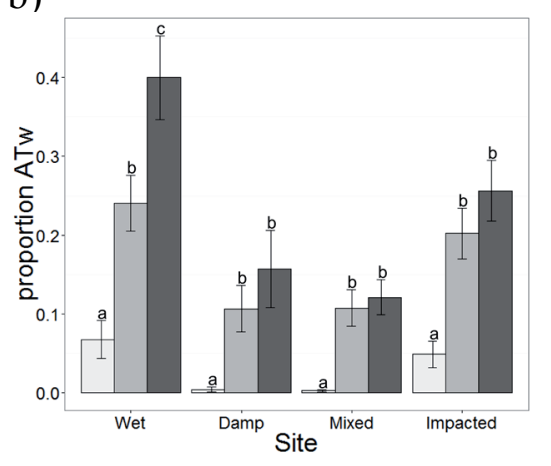

d)

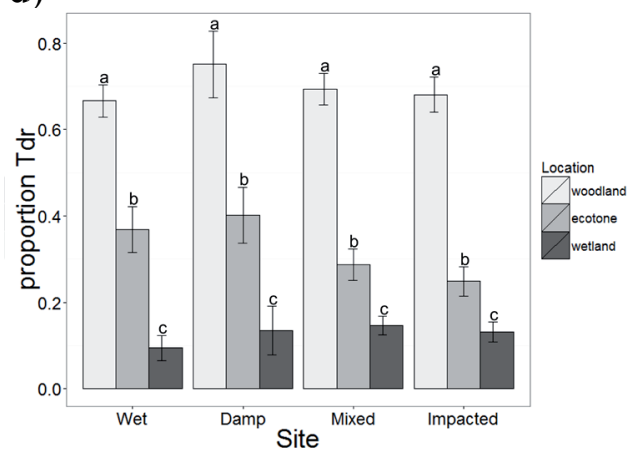

Figure 3. The proportion cover of each functional group a) Amphibious fluctuation-tolerators, emergent growth form (ATe), b) Amphibious fluctuation-tolerators, woody growth form (ATw), c) Terrestrial damp habitat spp. (Tda), and d) Terrestrial dry habitat spp (Tdr) in woodland, ecotone and wetland quadrats for each of the sites; within each site, letters indicate significant differences between locations.

cover indicate that most species are adapted to either a wet or dry environment with very few species spanning the length of the moisture gradient. Our results are consistent with evidence from other systems. Erdős et al. (2011) report intermediate species richness and diversity in the ecotone, which they also relate to changes in soil depth (as a proxy for soil moisture and nutrient content). Both Lloyd et al. (2000) and Walker et al. (2003) found intermediate species richness values in ecotones they investigated. Although our study does not provide conclusive evidence for intermediate ecotone properties, it adds weight to the argument that a greater or lesser number of species is not an intrinsic ecotone property.

In many cases, the species composition in ecotone areas differed from either the wetland or woodland, but rarely both. We found an mix of species from both the wetland and woodland in the ecotone and none of the water plant functional groups were confined solely to the ecotone. This differs from Erdős et al. (2011), who found that most species 
Table 5. ANOVA tables for the analysis of variance on linear models for soil characters at each site. Significant $(\mathrm{p}<0.05)$ terms are in bold.

\begin{tabular}{|c|c|c|c|c|c|c|}
\hline \multirow[b]{2}{*}{ Site } & & \multirow[b]{2}{*}{$\mathrm{df}$} & \multicolumn{2}{|c|}{ Change in soil moisture } & \multicolumn{2}{|c|}{ Change in soil depth } \\
\hline & & & SS & $\mathrm{F}$ & SS & $\mathrm{F}$ \\
\hline \multirow{2}{*}{ West Wolgan } & Location & 2 & 3.19 & 11.06 & 1.19 & 0.95 \\
\hline & Location:Transect & 3 & 9.25 & 17.41 & 6.07 & 3.25 \\
\hline \multirow{2}{*}{ Bungleboori North } & Location & 2 & 5.68 & 2.38 & 110.81 & 6.22 \\
\hline & Location:Transect & 9 & 72.32 & 6.74 & 90.1 & 1.12 \\
\hline \multirow{2}{*}{ Sunnyside East } & Location & 2 & 22.86 & 6.35 & 166.18 & 5.91 \\
\hline & Location:Transect & 33 & 204.76 & 3.45 & 1533.03 & 3.3 \\
\hline \multirow{2}{*}{ Narrow Swamp } & Location & 2 & 2.47 & 6.25 & 39.05 & 1.11 \\
\hline & Location:Transect & 16 & 7.19 & 2.27 & 728.04 & 2.59 \\
\hline
\end{tabular}

a)

b)
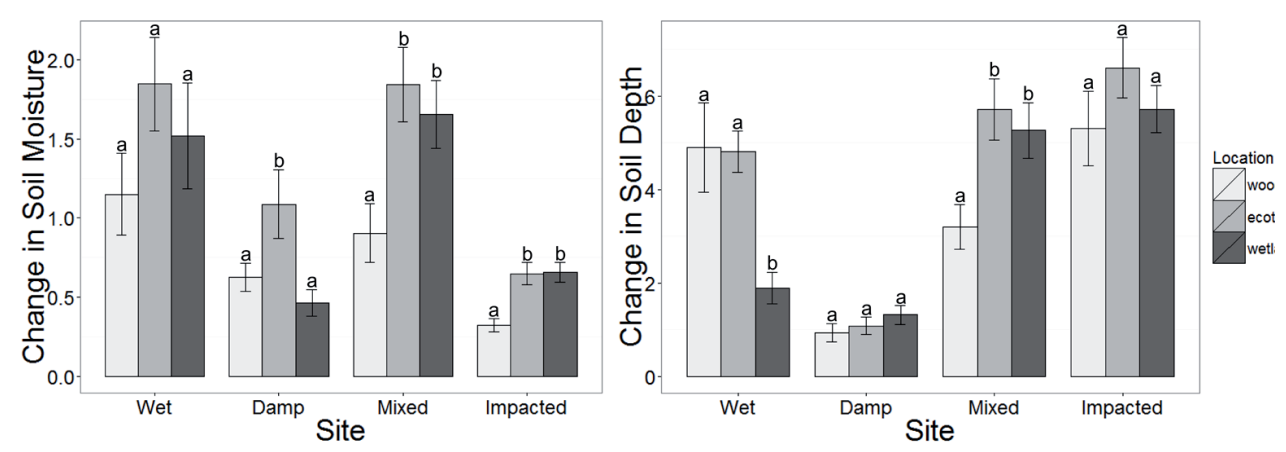

Figure 4. Comparison of rate of change in a) soil moisture, and b) soil depth in woodland, ecotone and wetland quadrats for each of the sites; within each site, letters indicate significant differences between locations.

in the ecotone came from a more species-rich community. Some authors have suggested that ecotones might contain characteristic species (i.e., "ecotonal species", Lloyd et al. 2000, Stohlgren et al. 2000, Erdős et al. 2011): a property of ecotones that would provide a focal point for monitoring of anthropogenic impacts in this wetland system. We found six species that only occurred in ecotone areas, although we doubt they are truly confined to the edge areas because 1) they are reasonably common across the Newnes Plateau and 2) for this survey these ecotone species were recorded at only one site. The lack of a characteristic ecotonal species is probably because the ecotone is an intergrade between the woodland/wetland rather than a transition zone containing unique environmental conditions (Lek-Ang et al. 2007).

While the specific properties of ecotones remain elusive, Mills et al. (2006) suggest that examination of ecotones can give insight into the ecological processes driving community assembly either side of the boundary. Through sampling across the vegetation gradients we were able to place the wetlands in ecological context. In the damp site both the number of functional groups and species richness were higher in the wetland than outside the wetland, while in the wet site the opposite was true. This probably reflects where along the soil moisture gradient these two wetland/woodland complexes sit.
The typical response is hump-shaped, with a greater number of species the middle of the gradient, with fewer species at the extremes (Grime 1973, Keddy 2010). For monitoring changes in vegetation we predict that the permanently wet wetland would potentially gain species as it dried, while the periodically wet wetland would potentially lose species. This is a key factor to consider when deciding on triggers for management actions, which through examination of ecotones, we were better able to understand.

Ecotones can also aide in the selection of indicator species for anticipated environmental changes (Stohlgren et al. 2000). Mills et al. (2006) suggest that the environmental factors that change the most between two communities will be the ones controlling species distributions. Unfortunately, to be of practical use as a monitoring tool, an indicator species must be both distributed widely and sensitive to change: creating a paradox that is rarely fulfilled. As an alternative, some authors have suggested a functional group approach might be more appropriate (Noble and Gitay 1996, Campbell et al. 2014). Here, the transition between terrestrial and amphibious functional groups also tended to occur in the ecotones, indicating ecotones probably represent the upper and lower tolerance limits of some species. A reduction in the abundance of amphibious functional groups (e.g., ATe and ATw) 
and increased abundance of Terrestrial dry land (Tdr) functional group in the ecotone could be used as an indicator of drying. The presence of functional groups have been used as indicators of wetland edges (Tiner 1991, Carter et al. 1994, Kirkman et al. 1998). Here we propose that changes in functional group abundance in ecotones could be an early indication of hydrological change.

While there have been many calls for a better understanding of these important transition areas (Stohlgren et al. 2000, Hofgaard et al. 2012), there is still a lack of a general predictive framework for ecotones (Ries et al. 2004). Multiple factors may influence the spatial and temporal structure of ecotones and it is difficult to predict the relative importance of each (Moen et al. 2008). While a lack of understanding of ecotones themselves currently limits their use for monitoring, by examining these transition areas we gained a better understanding of the environmental factors controlling species distribution either side and were able to propose indicators for monitoring for negative hydrological impacts.

Acknowledgements. Thanks to R. Blick and P. Bricher for assistance in the field. Thanks to C. Kilgour, P. McKenna and N. McCaffrey for assistance with plant identification.

\section{References}

Allen, C.D. and Breshears, D.D. 1998. Drought-induced shift of a forest-woodland ecotone: Rapid landscape response to climate variation. Proc. Natl. Acad. Sci. 95: 14839-14842.

Aune, S., Hofgaard, A. and Söderström, L. 2011. Contrasting climate- and land-use-driven tree encroachment patterns of subarctic tundra in northern Norway and the Kola Peninsula. Can. J. For. Res. 41: 437-449.

Batllori, E., Camarero, J.J. and Gutiérrez, E. 2010. Current regeneration patterns at the tree line in the Pyrenees indicate similar recruitment processes irrespective of the past disturbance regime. J. Biogeogr. 37: 1938-1950.

Benson, D. and Baird, I.R.C. 2012. Vegetation, fauna and groundwater interrelations in low nutrient temperate montane peat swamps in the upper Blue Mountains, New South Wales. Cunninghamia 12: $267-307$.

Brownstein, G., Döbert, T., Dobbie, L., Hashim, N. and Wilson, J.B. 2013. Functional traits shed new light on the nature of ecotones: a study across a bog-to-forest sequence. Community Ecol. 14: 31-40.

Cadenasso, M.L., Pickett, S.T.A., Weathers, K.C., Bell, S.S., Benning, T.L., Carreiro, M.M. and Dawson, T.E. 2003. An interdisciplinary and synthetic approach to ecological boundaries. BioScience 53: 717-722.

Campbell, C.J., Johns, C.V. and Nielsen, D.L. 2014. The value of plant functional groups in demonstrating and communicating vegetation responses to environmental flows. Freshw. Biol. 59: 858-869.

Carter, V., Gammon, P.T. and Garrett, M.K. 1994. Ecotone dynamics and boundary determination in the Great Dismal Swamp. Ecol. Appl. 4: 189-203.

Casanova, M.T. 2011. Using water plant functional groups to investigate environmental water requirements. Freshw. Biol. 56: 2637-2652.
Cornet, A.F., Montana, C., Delhoume, J.P. and Lopez-Portillo, J. 1992. Water flows and the dynamics of desert vegetation stripes. Landscape boundaries: Consequences for biotic diversity and ecological flows, New York: Springer-Verlag, pp. 227-345.

Danz, N.P., Frelich, L.E., Reich, P.B. and Niemi, G.J. 2013. Do vegetation boundaries display smooth or abrupt spatial transitions along environmental gradients? Evidence from the prairie-forest biome boundary of historic Minnesota, USA. J. Veg. Sci. 24: 1129-1140.

DEC. 2006. The Vegetation of the Western Blue Mountains. Hurstville: Department of Environment and Conservation.

Erdős, L., Gallé, R., Bátori, Z., Papp, M. and Körmöczi, L. 2011. Properties of shrubforest edges: a case study from South Hungary. Cent. Eur. J. Biol. 6: 639-658.

Erdős, L., Gallé, R., Körmöczi, L. and Bátori, Z. 2013. Species composition and diversity of natural forest edges: edge responses and local edge species. Community Ecol. 14: 48-58.

Fox, J. and Weisberg, S. 2010. An $R$ Companion to Applied Regression. SAGE.

Grime, J.P. 1973. Competitive exclusion in herbaceous vegetation. Nat. UK 242: 344-347.

Hofgaard, A., Harper, K.A. and Golubeva, E. 2012. The role of the circumarctic forest-tundra ecotone for Arctic biodiversity. Biodiversity 13: 174-181.

Keddy, P.A. 2010. Wetland Ecology: Principles and Conservation. Cambridge University Press, Cambridge.

Kirkman, L.K., Drew, M.B., West, L.T. and Blood, E.R. 1998. Ecotone characterization between upland longleaf pine/wiregrass stands and seasonally-ponded isolated. Wetlands 18: 346364.

Koleff, P., Gaston, K.J. and Lennon, J.J. 2003. Measuring beta diversity for presence-absence data. J. Anim. Ecol. 72: 367-382.

Lek-Ang, S., Park, Y-S., Ait-Mouloud, S. and Deharveng, L. 2007. Collembolan communities in a peat bog versus surrounding forest analyzed by using self-organizing map. Ecol. Model. 203: 9-17.

Liu, H. and Cui, H. 2009. Patterns of plant biodiversity in the woodland-steppe ecotone in southeastern Inner Mongolia. Contemp. Probl. Ecol. 2: 322-329.

Lloyd, K.M., McQueen, A.A.M., Lee, B.J., Wilson, R.C.B., Walker, S. and Wilson, J.B. 2000. Evidence on ecotone concepts from switch, environmental and anthropogenic ecotones. J. Veg. Sci. 11: 903-910.

Mathisen, I.E., Mikheeva, A., Tutubalina, O.V., Aune, S. and Hofgaard, A. 2014. Fifty years of tree line change in the Khibiny Mountains, Russia: advantages of combined remote sensing and dendroecological approaches. Appl. Veg. Sci. 17: 6-16.

McIntire, E.J.B. and Fortin, M-J. 2006. Structure and function of wildfire and mountain pine beetle forest boundaries. Ecography 29: 309-318.

Mills, A.J., Rogers, K.H., Stalmans, M. and Witkowski, E.T.F. 2006. A Framework for Exploring the Determinants of Savanna and Grassland Distribution. BioScience 56: 579-589.

Moen, J., Cairns, D.M. and Lafon, C.W. 2008. Factors structuring the treeline ecotone in Fennoscandia. Plant Ecol. Divers. 1: 77-87.

Noble, I.R. and Gitay, H. 1996. A functional classification for predicting the dynamics of landscapes. J. Veg. Sci. 7: 329-336.

OEH. 2012. Vegetation Information Systems: Maps. http://www.environment.nsw.gov.au/research/VISmap.htm. 
Oksanen, J., Blanchet, F.G., Kindt, R., Legendre, P., O’Hara, R.B. Simpson, G.L., Solymos, P., Henry, M., Stevens, H. and Wagner, H. 2011. vegan: Community Ecology Package version 1.17-8.

R Development Core Team. 2011. R: A Language and Environment for Statistical Computing. Vienna, Austria:

Ries, L., Jr. R.J.F., Battin, J. and Sisk, T.D. 2004. Ecological responses to habitat edges: Mechanisms, models, and variability explained. Annu. Rev. Ecol. Evol. Syst. 35: 491-522.

Stohlgren, T.J., Owen, A.J. and Lee, M. 2000. Monitoring shifts in plant diversity in response to climate change: a method for landscapes. Biodivers. Conserv. 9: 65-86.

Tiner, R.W. 1991. The concept of a hydrophyte for wetland identification. BioScience 41: 236-247.

van der Maarel, E. 1976. On the establishment of plant community boundaries. Berichte Dtsch. Bot. Ges. 89: 415-443.

Walker, S., Wilson, J.B., Steel, J.B., Rapson, G.L., Smith, B., King, W.M. and Cottam, Y.H. 2003. Properties of ecotones: Evidence from five ecotones objectively determined from a coastal vegetation gradient. J. Veg. Sci. 14: 579-590.

Williams, P.H., de Klerk, H.M. and Crowe, T.M. 1999. Interpreting biogeographical boundaries among Afrotropical birds: spatial patterns in richness gradients and species replacement. $J$. Biogeogr. 26: 459-474.

Received January 25, 2014 Revised September 18, 2014, March 31, 2015 Accepted November 4, 2015

\section{Electronic Appendix}

Figure A.1. Typical Newnes Plateau wetland.

Table A.1. The species list for the four sites, including functional group membership and species abundance in each location (woodland/ecotone/wetland).

The file may be downloaded from www.akademiai.com. 